\title{
RIBEIRO, Djamila. O que é lugar de fala?. Belo Horizonte: Letramento, 2017. 112 p. (Feminismos Plurais)
}

Thayanne Tavares Freitas*

*Universidade Federal do Rio Grande do Sul - Porto Alegre, RS, Brasil Doutoranda em Antropologia Social (bolsista CNPq) thay.tfreitas@gmail.com https://orcid.org/0000-0003-4128-4989 
Este livro, lançado por Djamila Ribeiro em 2017, é o primeiro de uma coleção chamada Feminismos Plurais, que pretende abranger as interseccionalidades das desigualdades a partir do olhar de autoras(res) negras(os). O projeto visa popularizar uma discussão que conjuga profundidade e uma escrita compreensível para um público diverso que queira se aproximar do debate em voga. Mestre em Filosofia, mulher negra e feminista, a autora traz em três capítulos o silenciamento e invisibilidade histórica da mulher negra, justamente por ter sido colocada na ultima posição de uma hierarquia social que atravessa $o$ gênero, a raça e a classe social.

Fica evidente no livro o diálogo da autora com mulheres acadêmicas, militantes e literatas. Partindo do pressuposto de que a autora se posiciona enquanto feminista negra e militante, esse local de fala faz com que ela se comprometa em viabilizar a visibilidade teórica dessas outras falas femininas na construção de um conhecimento que perpassa pela filosofia. Tal atitude política busca uma maior representatividade de teóricas negras e uma bibliografia de teorias produzidas por mulheres.

Djamila aponta para uma história que foi capaz de desumanizar a população negra, principalmente a mulher, fadada ao silêncio até mesmo nas pautas feministas universalizantes. O racismo, como protagonista de um cenário social, isolou a mulher negra e a reduziu a um corpo inexpressivo. Porém, não quer dizer que essa mulher negra não tivesse tentado falar, ela só não foi ouvida. O livro repensa qual é o lugar de fala dessas mulheres que estão presentes nos feminismos debatidos, apontando que não discutir esse múltiplo que vai além da mulher branca, cis e de classe média é silenciar os anseios de uma parcela considerável de mulheres que historicamente são colocadas na penumbra da "inexistência".

Após a apresentação, em que a autora situa a Feminismos Plurais, temos no primeiro capítulo diálogo com diversas autoras negras, além de outras referências: Truth, Gages, bell hooks, Audre Lorde, Giovana Xavier, Lélia Gonzalez, Linda Alcoff, dentre outras, com intuito de mostrar a dimensão do silenciamento e invisibilidade histórica das mulheres negras, que apesar de produzirem textos e discursarem sobre o feminismo, não eram ouvidas pela sociedade e muito menos pelo movimento feminista branco hegemônico da época (em meados do século XIX, como discorre Hill Collins, 2016). O que se compreende a partir dessa problemática é que as feministas que lideravam os debates eram brancas privilegiadas socialmente, portanto, não incluíam pautas que fossem além da concepção 
que elas tinham do que era ser mulher, afinal, mulheres negras (assim como os homens negros), haviam perdido a humanidade, ou melhor, a população negra era resumida ao corpo, um corpo com especificidades funcionais e que remetiam a sexualidade e não a produção de conhecimento (Gilman, 1985). Porém, não é mais possível universalizar a luta feminista, existem intersecções que criam camadas de hierarquias sociais que abrem um abismo entre mulheres brancas e negras.

Ainda nesse capítulo, Djamila traz evidências de que mesmo no feminismo denominado por primeira onda já existiam produções literárias e debates feitos por mulheres negras, mas que não eram ouvidas. Partindo desse pressuposto, a obra aponta para uma autoria inicial do feminismo feita por essas mulheres marginalizadas socialmente.

No segundo capítulo da obra, Djamila apresenta a mulher vista como se fosse o outro, o oposto do homem, que é a referência-padrão. Sobre isso Djamila dialoga com Beauvoir, trazendo a mulher enquanto o outro a partir do olhar masculino, criando uma relação subjugada e hierarquizada induzindo uma especificidade: a mulher pensada enquanto objeto que possui uma função.

Em um diálogo mais profundo sobre essa problemática e situando a mulher negra na discussão, Djamila pensa junto com Kilomba, na qual afirma que a mulher negra ao se diferenciar da branca e do homem, seria "o outro do outro", uma subcategoria duplamente subalternizada. Enquanto a mulher branca tem a chance de deixar de ser o outro e tornar-se um "para si", conforme diz Beauvoir, a negra nunca terá essa chance, pois ela sempre será esse outro.

Pensando com Kilomba, Djamila traz uma cadeia hierárquica social na qual no topo está o homem branco e na sequência a mulher branca, homem negro e por último a mulher negra. Sendo assim, universalizar a categoria mulher nas discussões, principalmente ao que se refere à busca por direitos, é também não situar essas mulheres, nem questionar que mulheres são essas. Tornar o debate homogêneo, desconsiderando as desigualdades presentes na constituição dessas mulheres, invisibiliza uma realidade que inferioriza essa mulher negra enquanto ser humano e torna ocultas problemáticas não vivenciadas por outrem.

Ainda nessa perspectiva, Djamila traz Sueli Carneiro para abordar sobre feminismo negro, mostrando que a pauta das mulheres brancas inicialmente era lutar pelo direito ao trabalho fora de suas residências. As mulheres negras que já tinham essa realidade em seus cotidianos não compreenderam a reivindicação. Portanto, essa mulher negra inserida no feminismo feito por mulheres 
brancas tornou-se um corpo estranho, o que deixa evidente a necessidade de visibilidade de problemáticas que abarcam essa diversidade de mulheres que buscam por direitos, pois aqui o gênero não é suficiente, a intersecção entre raça, classe social e gênero deve ser considerada para que essa pluralidade seja alcançada. É preciso ressignificar a identidade dessa mulher negra, colocando-a enquanto produtora de conhecimento e um ser político, pois até o momento ela é vista a partir de um racismo histórico.

Por fim, para abordar o lugar de fala em seu terceiro capítulo, Djamila dialoga com Audre Lorde ao mencionar que é preciso que as mulheres negras se posicionem enquanto seres que partem de uma realidade diferente, para que pautas não sejam uniformizadas. Além disso, é necessário que as mulheres brancas problematizem os seus lugares de fala e o quanto elas são privilegiadas, para que em um discurso fantasiado de "reivindicação dos direitos das mulheres" não excluam boa parte de suas companheiras de luta. Djamila aponta para uma questão bastante comum quando o termo "lugar de fala" é acionado nas discussões atuais, principalmente nas redes sociais digitais, nas quais igualam lugar de falar a representatividade. Partindo dessa relação, o lugar de fala torna-se um botão que ativa ou não o direito de falar sobre algo, ou seja, negros só falam sobre negros, mulheres sobre mulheres, homossexuais sobre homossexuais e daí por diante. É compreensível a afirmação: só compreende o que é racismo quem sofre com ele. Porém, quando se limita o debate a partir desse lugar que o outro não vivencia, a questão fica isolada ao entendimento de suas vítimas e não alcança as estruturas de poder.

Ampliar a discussão não significa abandonar esse lugar de fala, isso é impossível, pois todos nós partimos de um. É fundamental que a problematização vá além de quem é atingido por ela, pois faz com que esse outro pense na sua própria posição social. As mulheres negras, se restringissem que mulheres brancas tratassem sobre racismo, por exemplo, distanciariam a oportunidade de que essas mulheres repensem sobre suas responsabilidades na manutenção de subalternizações, o que faz com que elas se mantenham na posição cômoda de privilégios sem reflexão. Porém, essa fala precisa estar situada no seu lugar, ou seja, essa mulher branca ao falar sobre racismo deve compreender a sua posição e que o protagonismo de luta é da mulher atingida pelo racismo.

No entanto, Kilomba traz uma questão primordial. Precisamos falar! Historicamente nós mulheres negras fomos condenadas ao silêncio, caladas por sermos só um corpo sem conhecimento, porque não tínhamos necessidades 
a serem supridas, por não sermos humanas, silenciadas por sermos o outro e com funcionalidades específicas que não incluíam o pensar e o falar. Para concluir, Djamila aciona Conceição Evaristo, que traz a máscara como símbolo de opressão e que aprisionava a escrava Anastácia à fome e ao silêncio absoluto. Conceição Evaristo apresenta a fala como arma contra qualquer opressão. Logo ela, que aos 71 anos de idade concorreu à vaga da cadeira número 7 da Academia Brasileira de Letras. Conceição Evaristo leva consigo uma multiplicidade de mulheres negras e todas nós em um só coro gritamos: existimos!

A escrita de Djamila me fez refletir sobre as minhas vivências e me trouxe inúmeras imagens que remetem a outras trajetórias, uma delas foi de uma mulher recentemente silenciada pela injustiça, pelo racismo e pela ameaça que foi ser ouvida. Marielle Franco com a força da sua fala foi condenada ao silenciamento, assim como muitas outras mulheres negras o são diariamente, mas ela deixou um legado. É preciso falar e enquanto tivermos forças falaremos.

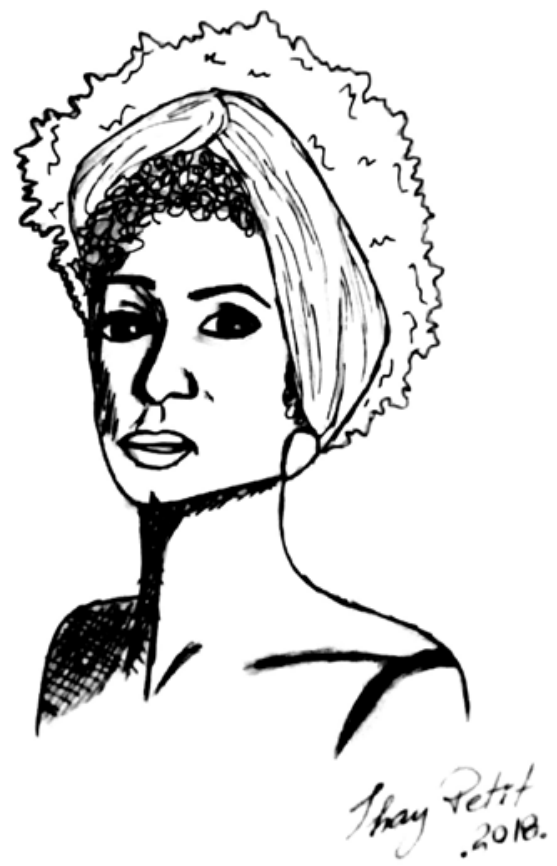

Figura 1. Marielle Franco (ilustração da autora). 


\section{Referências}

GILMAN, S. L. Black bodies, white bodies: toward an iconography of female sexuality in late nineteenth-century art, medicine, and literature. Critical Inquiry, v. 12, n. 1, p. 204-242, 1985.

HILL COLLINS, P. Aprendendo com a outsider within: a significação sociológica do pensamento feminista negro. Sociedade e Estado, v. 31, n. 1, p. 99-127, 2016. 